\title{
Perceptual aspects of the use of faucets (taps)
}

\author{
Lívia F. de A. Campos ${ }^{\mathrm{a}^{*}}$, Luis Carlos Paschoarelli ${ }^{\mathrm{a}}$ \\ ${ }^{a}$ PPGDesign, Fac. of Architecture, Arts and Communication, UNESP - Univ Estadual Paulista, Av. Eng. Luis E. \\ C. Coube, 14-01, 17033-360, Bauru, Brazil
}

\begin{abstract}
This paper presents an assessment with simulated activities with the aim of analyzing the perception of ease / difficulty of the use of faucets (taps) handles by 180 Brazilian adults. Five different handles faucets were activated for subsequent collection of perceptual data. The procedures were based on main recommendations for biomedical ethics and human research. The results indicate that handles with levers are significantly $(\mathrm{p} \leq 0.05)$ easier to use. The most difficult are characterized by not having support points for the rotation (levers) or more points of pressure concentration in the hand.
\end{abstract}

Keywords: Design, ergonomics, usability, perception, hand tools.

\section{Introduction}

The ergonomic design performs an important role in maximizing the functionality of a product and ensuring its usability. Among the interfaces that require studies in ergonomics, which are used in work or activities of daily life, the hand tools stand out to perform tasks that require more precision and more power than the hand of a person could provide [21], or to serve as the physical support of management which is the form of 'coupling' that occurs between man and machine, whereby it becomes possible for man to transmit commands to the machine, or any other drive [8].

The lack of usability in interfaces such as faucet (taps in UK) handles - where usability aspects are not always taken into account, and outweigh the aesthetic and symbolic - can favor the emergence of usability problems, such as discomfort and dissatisfaction.

The variables of importance in this type of interface involves, beyond the capacity of the musculoskeletal system, interactions that occur at the level of sensory processes, which are responsible for promoting feelings of well being and user satisfaction with the product.

This paper presents an ergonomic evaluation with simulated activities, with the aim of analyzing the perceived level of ease or difficulty of use of five different models (designs) of faucets handles, where- as this information is of great relevance to the ergonomic design of these interfaces.

\section{Theoretical review}

The metal fittings are in the full line of utensils and equipment found in kitchens, bathrooms, toilets and service areas, such as faucets, shower mixers, flush valves, hydraulic registers, and accessories (soap dishes, towel racks, hangers, paper, etc.). Through the handles of the faucets occur the interface User $x$ Product in the activation of faucets, mixers and hydraulic registers [12].

In Brazil we observe that in many cases, the design of this interface constitutes the 'new reading' of products developed abroad and have a tendency to minimalism, with straight shapes, geometric, simplified and symmetrical [12]. This trend can be configured purely in the symbolic, that in many cases is far from the actual skills and needs of users.

The analysis of this interface (which aims the investigation of issues related to usability, performance and security in the use of these products) has contemplated, the human physical capabilities and limitations, such as knowledge of forces involved in manual handling [13].

However, besides the problems related to the ability of the musculoskeletal system, a subjective evalu-

\footnotetext{
*Corresponding author. Tel. no. +55 14 31056057. Email: liviaflavia@gmail.com
} 
ation of subjects' perception represents another set of factors that can help the ergonomic approach [17].

Although it is relevant, the physical measurement does not consider the particular difficulty of performing the action or the individual's ability. Perceptual estimates give important information because the task difficulty intensity depends on who executes the action [6].

Perceptual dimensions have been included in several evaluations of ergonomic hand tools usability [20] [1] [9] [15] [7] [14]. A study was conducted to investigate the perceptual dimensions in the use of doorknobs. A graphic scale was used to rate the ease / difficulty of using. The study showed that doorknobs with lever are easier to use and the spherical and cylindrical are more difficult to be used [16].

\section{Materials and Methods}

\subsection{Ethical questions}

This study was approved by the Ethics Committee of USC/Bauru - SP (Protocol 005/09 of 20/022009), it serves the resolution 196/96-CNS-MS, the National Health Council (CNS, 1996) [4] and the standard "ERG BR 1002", from "Code of Ethics of the Certified Ergonomist" [2].

\subsection{Subjects}

The sampling definition was based on the theory of statistical inference, and the principle of sample's independence about the population [19]. The total was 180 adults (over 18 years) of both genders.

The average age of subjects was 44.67 years (s.d. 20.05 years old), the average weight was $66.45 \mathrm{~kg}$ (s.d. $16.31 \mathrm{~kg}$ ) and the average height was $157.00 \mathrm{~cm}$ (s.d. $6.00 \mathrm{~cm}$ ).

\subsection{Materials}

A structure to operate the faucet handles with standardized height of $1.00 \mathrm{~m}$ from the floor [3] (simulating the opening of a shower), a graphic scale to collect the perceptual data (Figure 1A) and five different faucet handles (Figure 1B) were used for data collection.

A Free and Clarified Consent Term (TCLE), a recruitment protocol, an identification protocol, and a protocol for perceptual data registration were also applied.

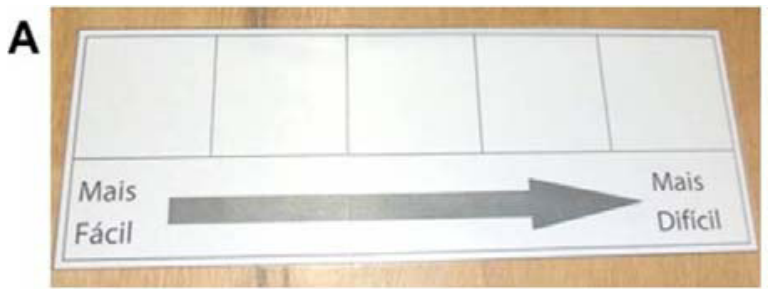

B

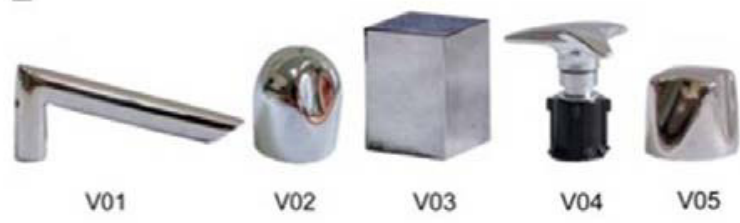

Fig 1 - A: Scale graphics to collect perceptual data (From "easier" to "harder"). B: handles of taps used in the test.

\subsection{Procedures}

The study objectives were explained to subjects individually. They read, completed and signed the TCLE and the identification protocol.

The simulation activity began after collecting weight and height. It consisted in operating the five handles and realizing maximum strength. The handles sequence was randomized and an interval of 60 seconds was applied between them.

After the simulation, the subjects were requested to organize the handles on the graphic scale, from easiest to hardest. The procedures were standardized [22], based on ethical recommendations [4] and biomedical criteria [18] [5] [11].

\subsection{Statistical analysis}

The collected data consisted of the values assigned to each knob score based on its position (1st place $=$ 1 , 2nd place $=2 \ldots$..). The graphic scale ranged from 1 (easiest) to 5 (hardest). The results were analyzed statistically.

By the analysis of significant differences, the attendance to the assumptions of normality condition of variances (Shapiro -Wilk) was noticed, and when there is no answer to this assumption it leads to a non-parametric analysis (Wilcoxon $-\mathrm{p} \leq 0.05$ ).

\section{Results}

The handle lever (V01) was considered the easiest to use and the spherical handle (V02) was the most difficult (Figure 2). 


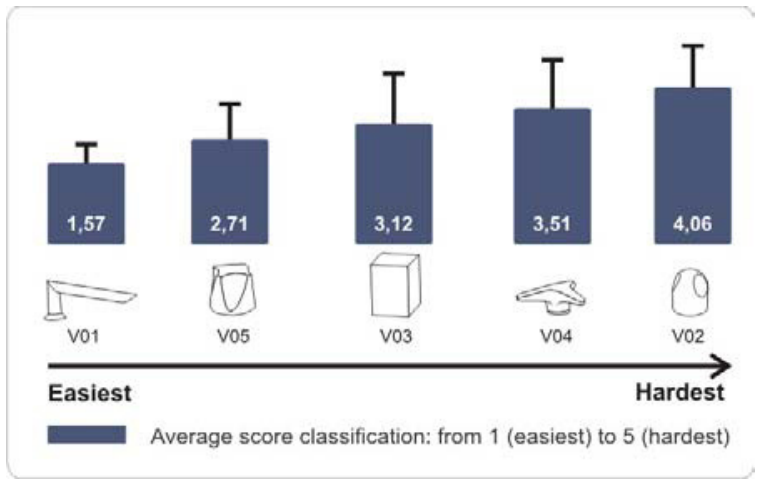

Fig 2 - Results (average and standard deviation) of the perceived ease/difficulty of the use of handles.

Statistical analysis showed significant differences in all comparisons (Wilcoxon $-\mathrm{p} \leq 0.05$ ), as shown in Table 1 .

Table 1

Values of "p" for the Wilcoxon test $(\mathrm{p} \leq 0.05)$

\begin{tabular}{|l|l|l|l|l|}
\hline & $\mathrm{V} 05$ & $\mathrm{~V} 04$ & $\mathrm{~V} 03$ & $\mathrm{~V} 02$ \\
\hline $\mathrm{V} 01$ & $\mathrm{p}=0.0000^{*}$ & $\mathrm{p}=0.0000^{*}$ & $\mathrm{p}=0.0000^{*}$ & $\mathrm{p}=0.0000^{*}$ \\
\hline $\mathrm{V} 02$ & $\mathrm{p}=0.0000^{*}$ & $\mathrm{p}=0.0003^{*}$ & $\mathrm{p}=0.0000^{*}$ & \\
\hline V03 & $\mathrm{p}=0.0004^{*}$ & $\mathrm{p}=0.0361^{*}$ & & \\
\hline V04 & $\mathrm{p}=0.0000^{*}$ & & & \\
\hline
\end{tabular}

These results are discussed in the next topic.

\section{Discussions}

The results showed that handles with lever (V01) and smooth cuts (V05) are significantly easier to use. On the other hand, the V03 and V04 handles have morphological structure which, in theory, could also provide facilitated prehensions, mainly due to the draw with different support points. However, the presence of edges and corners, may have contributed to significant pressure on the palm side of the hand, making the user experience more uncomfortable.

The handle V02 was more difficult to use, probably due to its spherical shape that reduces the pressure points in hand, but does not allow handling to facilitate the spin, because it has no support points.

The results are similar to those shown in the study of doorknobs [16], in the evaluation of perceived usability of hand tools.

\section{Final comments}

This study aimed to perform simulated evaluation activities, and analyze the ease / difficulty perception of the use of faucet handles, considering that, beyond the physical aspects, usability also includes the perceptive aspects.

The ergonomic design of these interfaces should prioritize shapes that have support points (levers) and avoid spherical settings and those with straight edges. This information is fundamental to achieve accessibility and usability of this interface and others that require activation through manual torque.

\section{Acknowledgements}

This study was supported by CNPQ - National Council for Scientific and Technological Development (Proc. 303138/2010-6); and FAPESP - São Paulo Research Foundation (Proc. 2009/02125-0; 2010/20439-9; 2005/59941-2).

\section{References}

[1] A. Chao, A. J. Kumar, C. T. N. D. Emery, K. Nagarajarao and H. You. An ergonomic evaluation of cleco pliers. In: Ergonomics for the New Millennium. Proceedings of the IEA 2000/HFES 2000 congress. San Diego, 2000, p. 441-442.

[2] ABERGO. Brazilian Ergonomics Association. Norma ERG BR 1002 - Code of Ethics of the Certified Ergonomist. Available in:

http://www.abergo.org.br/arquivos/normas_ergbr/norma_erg br_1002_deontologia.pdf> [2003]. Accessed in: 8, Aug, 2009. [In portuguese]

[3] ABNT - Brazilian Association of Technical Standards. NBR 9050: Accessibility to buildings, furniture, and spaces and urban-wireless network equipment. Rio de Janeiro, 2004, p. 105. [In Portuguese]

[4] CNS. National Health Council 1996, Resolution No. 196, October 10, 1996. Available at: $<$ http://conselho.saude.gov.br/docs/Resolucoes/Reso196.doc $>$. Accessed: 8, Apr, 2010. [In Portuguese]

[5] D. B. Chaffin. Ergonomics guide for the assentment of human strength. Amer. Ind. Hyg. J, (36), 1975, p. $505-510$.

[6] G. Borg. Borg's perceived exertion and pain scales. Human Kinetics, ed, Champaign: 1998.

[7] H. You, A. Kumar, R. Young, P. Veluswamy and D.E. Malzahn. An ergonomic evaluation of manual Cleco plier designs: Effects of rubber grip, spring recoil, and worksurface angle. Applied Ergonomics, 36, 2005, p. 575-583.

[8] I. Iida. Ergonomics: design and production. Edgard Blucher, ed, São Paulo, 2005. [In Portuguese]

[9] J. L. Boyles and R. D. Yearout and M. J. Rys. Ergonomic scissors for hairdressing. International Journal of Industrial Ergonomics, 32, 2003, p. 199-207.

[10] J. Nielsen. Usability Engineering. Academic Press, ed, Boston, 1993. 
[11] K. H. Kroemer, H. Kroemer and K. Kroemer-Elbert. Ergonomics: how to design for exertions. Human Factors, 12 (3), 1994 , p. $297-313$.

[12]L. F. A. Campos and L. C. Paschoarelli. Taxonomy of the handle of forms of metals of bathroom and kitchen. In: Proceedings of the X ERGODESIGN. Rio de Janeiro, LEUI PUC - Rio, 2009 [CD-ROM]. [In Portuguese]

[13]L. F. A. Campos Assessment of manual forces in simulated manual activities with Brazilian adults of different genders and age groups: ergonomic aspects of design. Dissertation. FAAC - UNESP - Bauru, 2010. [In Portuguese]

[14] L. F. M Kuijt-Evers, P. Vink and M. P. de Looze. Comfort predictors for different kinds of hand tools: Differences and similarities. International Journal of Industrial Ergonomics, 37 , 2007, p. 73-84.

[15] L. Groenesteijn, S.M. Eikhout and P. Vink. One set of plier for more tasks in installation work: the effects on (dis)comfort and productivity. Applied Ergonomics, 35, 2004, p. 485-492.

[16] L.C. Paschoarelli. Ergonomic Design: assessment and analysis of hand tools in interface User $\mathrm{x}$ Technology, Thesis Habilitation. FAAC - UNESP - Bauru, 2009. [In Portuguese]
[17] L.C. Paschoarelli. Usability applied to the ergonomic design of ultrasound transducers: a methodology for assessment and analysis of the product. Thesis, UFSCar, 2003. [In Portuguese]

[18]L.S. Caldwell, D. B. Chaffin, F. N. Dukes-Bobos, K.H.E. Kroemer, L.L. Laubach, S.H. Snook and D. E. Wasserman. A proposed standard procedure for static muscle strength testing. American Industrial Hygiene Association Journal, 35, 1974, p. 201-206.

[19]M. F. Triola. Introduction to Statistics. LTC, ed, Rio de Janeiro, 1999, p. 149.

[20] M. Jung and M.S. Hallbeck. Ergonomic redesign and evaluation of a clamping tool handle. Applied Ergonomics, 36, 2005, p. 619-624.

[21] S.N. Chengalur, S. Rodgers and T.E. Bernard. Kodak's: ergonomics design for people at work. John Wiley \& Sons, ed, New Jersey, 2004, p.342.

[22] V. Mathiowetz, N. Kashman, G. Volland, K. Weber, M. Dowe and S. Rogers. Grip and pinch strength: normative data for adults. Archives of Physical Medicine and Rehabilitation, 66,1985 , p. 69-74. 